\title{
Políticas de formação do alfabetizador e produção de políticas curriculares: pactuando sentidos para formação, alfabetização e currículo
}

\author{
Education policies for literacy teachers and \\ curricular policies development: agreeing on \\ meanings for education, literacy and curriculum
}

\section{Políticas de formación del alfabetizador y producción de políticas curriculares: estableciendo relaciones de sentidos para formación, alfabetización y currículo}

\author{
Rita de Cássia Prazeres Frangella*
}

Resumo: Este artigo discute o Pacto Nacional pela Alfabetização na Idade Certa PNAIC (2012), programa instituído pelo Ministério da Educação que visa assegurar que todas as crianças estejam alfabetizadas até os oito anos de idade e que tem como ação prioritária a formação do professor alfabetizador. Argumenta-se que a produção de políticas é luta por significação que envolve diferentes discursos que se articulam na produção de um discurso pedagógico que, em busca de qualidade, nesse caso, significa o investimento na formação de professores como instituidores de políticas curriculares. Analisam-se os documentos referentes ao PNAIC e outros com os quais ele se relaciona, interrogando os sentidos de formação, currículo e alfabetização que deles se depreendem, observando o deslocamento/deslizamento do que se considera, neste artigo, núcleo de significação importante para as propostas: o direito à aprendizagem. Daí se desdobra a valorização das discussões metodológicas/procedimentais, em uma centralidade da dimensão do ensino que se observa na proposta.

Palavras-chave: PNAIC. Formação do alfabetizador. Currículo.

\begin{abstract}
This paper discusses the Pacto Nacional pela Alfabetização na Idade Certa PNAIC/2012 (National Pact for Literacy at the Right Age), a program established by the Ministry of Education, which aims to ensure that all children are literate by the age of eight and focuses on literacy teacher education as a priority action. It is argued that policy development is a fight for meaning, involving different discourses interconnected in a pedagogical discourse production that, seeking quality, means investment on teachers'
\end{abstract}

* Professora da Universidade do Estado do Rio de Janeiro (UERJ). ProCientista UERJ, Jovem Cientista do Nosso Estado/FAPERJ. E-mail: <rcfrangella@gmail.com> 
education as curricular policy establishers. PNAIC documents and the ones related to it are analyzed through the investigation of meanings of education, curriculum and literacy that they reveal, observing a shift in what it is considered, in this paper, the core of the meaning of the proposals: the right to literacy. From there, the appreciation of methodological/procedural discussions unfolds, in a central dimension of teaching observed in the proposal.

Keywords: PNAIC. Literacy teacher education. Curriculum.

Resumen: Este artículo discute el Pacto Nacional para la Alfabetización en la Edad Apropiada (PNAIC - 2012), programa instituido por el Ministerio de Educación cuyo objetivo es asegurar que todos los niños estén alfabetizados hasta los ochos años de edad y que tiene como acción prioritaria la formación del profesor alfabetizador. Se argumenta que la producción de políticas es una lucha por significación, que involucra distintos discursos que se articulan en la producción de un discurso pedagógico que, en busca de calidad, en este caso, significa la inversión en la formación de profesores como instituyentes de políticas curriculares. Se analizan los documentos que se refieren al PNAIC y otros con los cuales se relaciona, interrogando en ellos los sentidos de formación, currículo y alfabetización que de ellos se construyen, observando el desplazamiento/deslizamiento de lo que se considera núcleo de significación importante para las propuestas: el derecho al aprendizaje. De ahí surge el desdoblamiento de la valoración de las discusiones metodológicas/procedimentales, en una centralidad de la dimensión de la enseñanza que se observa en la propuesta.

Palabras clave: PNAIC. Formación del alfabetizador. Currículo.

\section{Investir na formação, instituir currículo - objetivos cruzados}

Se todo o projeto fosse o objeto tranquilizador, a consequência lógica ou teórica de um saber assegurado (eufórico, sem aporia, sem contradição, sem indecibilidade para resolver), isso seria uma máquina e funcionaria sem nós, sem responsabilidade, sem decisão, no fundo, sem ética, nem direito, nem política. Não há decisão nem responsabilidade sem a prova da aporia ou da indecibilidade. (DERRIDA, 2004, p. 322).

A palavra de ordem hoje é a busca por qualidade. Sem dúvida, é um discurso articulador potente e que se desdobra em múltiplas facetas, uma delas, não tão nova, mas que em geral se apresenta como ponto fulcral para que se alcance tal objetivo: formação de professores.

No campo do currículo, esse discurso é enfatizado em muitas pesquisas que, em suas conclusões, apontam como principal proposição a necessária re- 
formulação e/ou inserção de propostas de formação docente (MACEDO et al., 2007). A busca por uma "[...] educação de qualidade referenciada no social" (BRZEZINSKI, 2014, p. 7) faz-se em consonância com o interesse na formação e na valorização dos profissionais da Educação.

Tal perspectiva chama atenção para o contexto de reformas educacionais, que se fazem presentes no cenário contemporâneo como condição sine qua non de alcance de melhoria na qualidade da Educação. Assim, o sentido de reforma vem imbuído de mudanças que, por si só, gerariam resultados que se coadunam com os objetivos de melhoria traçados, em uma marca contundente de positividade. Se "reforma" é a palavra de ordem, a ela se associa também outra palavra de ordem: "formação". De certa forma, as reformas educacionais que focalizam a formação de professores pretendem, de forma direta, "reformar" a formação e os professores.

No que diz respeito especificamente à formação de alfabetizadores, a temática, da mesma forma como é tratada na análise do campo do currículo, é reafirmada como estratégia de possibilidade de reversão da problemática observada na prática cotidiana: a reformulação de propostas para a formação docente qualificando a partir daí a ação dos alfabetizadores.

Temos assistido a uma trajetória de propostas de formação, principalmente continuada, de alfabetizadores como foco de políticas públicas como o Programa de Formação de Alfabetizadores (PROFA) e o Pró-letramento. Contudo, essas propostas não têm sido tão focalizadas nos diferentes estudos sobre a alfabetização. Chama atenção que, em um levantamento exploratório dos trabalhos apresentados nas últimas três Reuniões anuais da ANPEd (Natal, 2011; Porto de Galinhas, 2012; Goiânia, 2013) no GT 10 - Alfabetização, Leitura e escrita - somente 2 trabalhos tenham sido apresentados sobre a questão, um em 2011 (LUCIO, 2011) e outro em 2013 (ALMEIDA; TASSONI, 2013). No GT 08 - Formação de professores -, apenas um trabalho em 2011 (BAUER, 2011). Inferência reafirmada ao se considerar os dados apresentados no recente estudo publicado na série "Estado do Conhecimento", do Instituto Nacional de Estudos e Pesquisas Educacionais Anísio Teixeira (INEP): Formação de profissionais da Educação (2003-2010). Nele, observa-se que, ainda que o estudo tenha sido desenvolvido a partir de uma amostragem significativa da produção de alguns programas (18 na produção relativa a 2003-2007 e 17 na produção relativa aos anos de 2008-2010) das diferentes regiões brasileiras, no período de 2003-2007, quando foram analisados 574 teses e dissertações, destas 13 colocam em discussão a formação do alfabetizador. No período 2008-2010, foram analisados 284 teses e dissertações - destas apenas 3 focalizavam a formação do alfabetizador. 
Assim, destaco a importância da análise de políticas públicas para a formação de alfabetizadores, vistas em diálogo com o contexto de produção de políticas públicas para a Educação em que se articulam. Ao fazer tal defesa, insiro-me nesse movimento a partir de uma trajetória de pesquisa sobre a produção de políticas curriculares para o ensino fundamental no município do Rio de Janeiro, onde observo a criação de uma rede interligada de formação continuada de professores, atendendo a reinvindicações e dispositivos legais, atrelada à produção de políticas curriculares na rede. No município em tela, as propostas de formação continuada para professores alfabetizadores têm, ao longo da última década, impactado a produção da própria rede, na articulação com propostas curriculares que colocaram em foco a organização dos anos iniciais em ciclo e concepções de alfabetização, leitura e escrita que aí se cruzavam. O que pode se observar na trajetória da pesquisa é como a formação põe-se a serviço da política curricular, não como espaço de reflexão e recriação, tradução da proposta, mas de forma a garantir a instituição dessa política na prática cotidiana.

Hoje se observa os movimentos da rede em torno do Pacto Nacional pela Alfabetização na Idade Certa (BRASIL, 2012a) - PNAIC, programa instituído pelo Ministério da Educação em parceria com Estado e municípios que visa assegurar que todas as crianças estejam alfabetizadas até os oito anos de idade, ao fim do terceiro ano do Ensino Fundamental. Pela sua abrangência e por ser apresentado como ação estratégica no âmbito das políticas educacionais para o Ensino Fundamental, justifica-se a relevância e a importância de tomá-lo para análise. Chama atenção a extensão, a abrangência e a adesão ao Pacto. Os dados fornecidos pela Secretaria de Educação Básica (SEB) ${ }^{1}$ do Ministério da Educação (MEC) afirmam que estão envolvidos no programa 317 mil professores alfabetizadores, 15 mil orientadores de estudo, 5.420 municípios, 38 universidades públicas nos 26 Estados e Distrito Federal. No caso do Rio de Janeiro, há 100\% de adesão dos municípios fluminenses.

Sem dúvida, uma das questões que vem tendo destaque nas discussões acerca da produção da educação pública entrelaça a questão da alfabetização, do desenvolvimento da competência leitora e escritora de crianças, jovens e adultos. Constantemente alardeados pela mídia, a partir de resultados, sem dúvida expressivos, de diferentes avaliações e comparações internas e externas, observamos crianças que concluem os anos iniciais sem saber ler/escrever, jovens que também dominam tais conhecimentos básicos, políticas de correção de fluxo, de aceleração e outras sendo produzidas a partir dessa realidade.

Se a situação é alarmante, ela demanda que ações profícuas sejam tomadas para que possamos enfrentar o problema e buscar caminhos para a reversão do

\footnotetext{
${ }^{1}$ Dados disponíveis em: <http://portal.mec.gov.br/index.php?option=com_content\&view=article\&id=124 92\&Itemid=811>. Acesso em: 5 out. 2014.
} 
quadro. Durante muito tempo, a busca por culpados marcou a questão. Nesse caso, em geral, professores ocupam esse lugar, seja por desconhecimento, insuficiente formação ou outra questão. Ao mesmo tempo, vários estudos apontam que a questão requer um tratamento complexo dada a multiplicidade de fatores que interferem na produção dessa situação. Esse contexto abre-se como terreno fértil para que um pacto social fosse assumido. Há de se fazer algo, isso é certo. Mas o quê? Com que sentido?

Assim, o investimento no Pacto pela Alfabetização na Idade Certa, que concentra seus esforços prioritariamente na formação continuada de professores alfabetizadores, dá-se concomitantemente em um contexto onde pululam questões que devem ser mais discutidas e aprofundadas, no debate sobre a definição de um currículo nacional, assentada na ideia de base comum nacional, como vem sendo amplamente anunciado na mídia e por organizações não-governamentais com intensa atividade no campo da Educação ${ }^{2}$. Nesse caso, a alfabetização figura como um dos focos dessa construção.

Trata-se de um processo que não se dá como coincidência temporal ou ações paralelas, mas uma intrincada rede de significações cruzadas que nos convocam a pactuar por uma educação de qualidade e que, para tanto, o nosso pacto dá-se com a formação e o currículo. Argumento que em busca da qualidade, há uma miríade de sentidos em disputa, em uma pluralidade de demandas sociais que se articulam em torno do significante vazio, nesse caso qualidade, tal como estudos de Macedo (2009) e Lopes (2012) também defendem. Daí discuto essa complexa relação, pensando a formação de professores como instância de produção curricular e não como questão correlata.

A proposição de analisar a partir de tal recorte a produção de políticas de formação de professores e curriculares assenta-se em uma perspectiva discursiva que permite inferir as políticas como produções político-discursivas. Assim sendo, observar as demandas e as articulações que produzem uma dada formação discursiva - que não se trata de um conjunto amorfo ou constituído por justaposição; ao contrário, trata-se do alinhamento complexo de demandas que tensionadas e articuladas permitem que um discurso se hegemonize -, potencializa a análise das articulações que constituem a produção de políticas públicas para a Educação.

\footnotetext{
${ }^{2}$ Aqui faço menção a organizações como a Fundação Lemmann, Todos pela Educação, Plataforma do Letramento (Fundação Volkswagen/Cenpec), entre outras. Ao rastrear as ações desenvolvidas por essas organizações, é possível acompanhar o impacto de suas ações no campo educacional. A fim de esclarecer o que argumento, destaco uma das áreas de atuação da Fundação Lemmann assim apresentada no site: "Políticas educacionais - apoiar e fomentar pesquisa de alta qualidade sobre políticas educacionais + disseminar informações educacionais relevantes para gestores, professores, formadores de opinião e família $=$ Tomadas de decisão baseadas em evidências da área educacional”. Disponível em: <http://www.fundacaolemann.org.br/ quem-somos>. Acesso em: 3 out. 2014.
} 
Dessa forma, ponho em relevo a observância da produção de políticas como uma luta política por significação, que envolve diferentes discursos que se articulam. Dentre eles, os discursos por formação de professores que se dão também como momento de produção de políticas curriculares. O que argumento, a partir do diálogo com autores como Derrida (2001), Bhabha (2003) e Laclau (2011), é em relação ao deslocamento/deslizamento de significantes como formação e políticas curriculares, os quais se articulam na produção de um discurso pedagógico que, em busca de qualidade, significam o investimento na formação de professores como instituidores de políticas curriculares. Como Macedo (2009), busco discutir:

[...] que a articulação desses discursos tem sido possível em função de um exterior constitutivo relacionado à pressão das demandas da diferença sobre a escola e o currículo, também elas articuladas em função do antagonismo radical de discursos universalizantes. Dessa forma, tanto uma como outra cadeia de equivalências, em processos de articulação e rearticulação hegemônicos, tentam preencher o significante qualidade, o que só são capazes de fazer provisoriamente. (MACEDO, 2009, p. 95, grifo do autor).

É importante evidenciar a perspectiva na qual me ancoro para fazer tais questionamentos. O entendimento do currículo como campo de produção cultural, espaço-tempo de negociações que hibridizam discursos, inclui aí concepções e práticas produzidas nos diferentes contextos que concorrem para sua produção. Uma produção multifacetada que não se encerra na esfera de produção do texto da política, mas envolve contextos de influência e a prática cotidiana desenvolvida nas escolas, não como fornecedores de dados, mas partícipes do processo.

Ao operar a partir dessa compreensão, e no diálogo com Bhabha (2003) ao referir-me a currículo como enunciação, assumo que currículo é movimento, diferimento, significação. Como produção político-discursiva, o currículo é terreno de luta política pela significação que mobiliza o eu e o outro, ou seja, processo dialógico cujos sentidos não são e nunca serão transparentes, pois são produzidos em meio à negociação, à articulação. $\mathrm{O}$ que se produz ao produzir currículo não é uma visão ou outra, mas uma produção híbrida que já não é mais nem um nem outro, à medida que o eu e o outro aí referenciados alusivamente não são inimigos em luta, mas adversários legítimos em disputa. Esse processo contingente é cultural, ato de enunciação cultural.

Assim, observando a trajetória das políticas educacionais propostas para os anos iniciais, faz-se necessário discutir as relações entre formação de professores, políticas curriculares e alfabetização em um contexto em que esta figura como demanda crescente e foco de produção. Isso pode ser observado na análise do Plano Nacional de Educação (PNE) (BRASIL, 2014) que é apresentado com espírito de uma política de Estado de Educação para a próxima década. O Plano tem entre suas metas: 
Meta 5: alfabetizar todas as crianças, no máximo, até o final do $3^{\circ}$ (terceiro) ano do ensino fundamental.

[...] Entre as principais estratégias registradas no PNE para o cumprimento da Meta 5, situa-se a estruturação de processos pedagógicos nos anos iniciais do ensino fundamental em articulação com estratégias que deverão ser desenvolvidas pela pré-escola com qualificação e valorização dos professores alfabetizadores e com apoio pedagógico específico, a fim de garantir a alfabetização plena de todas as crianças (Estratégia 5.1). Nesse sentido, está proposto o fomento ao desenvolvimento de tecnologias educacionais e de inovação das práticas pedagógicas, bem como a seleção e divulgação das tecnologias que sejam capazes de alfabetizar e de favorecer a melhoria do fluxo escolar e a aprendizagem dos alunos. (BRASIL, 2014, p. 24).

Como se observa no PNE, aprovado em 25 de junho de 2014, após 2 anos de debates, a articulação formação-currículo-alfabetização apresenta-se com força, inclusive dado que as metas elencadas são assumidas como eixos estruturantes do Pacto Nacional pela Alfabetização na Idade Certa.

\section{Formação e currículo sob rasura...}

Ao tematizar sobre formação de professores e políticas curriculares, faço-o em um alinhamento à questão que tem sido considerada nas pesquisas que venho desenvolvendo: Que demandas produzem articulações que significam as políticas curriculares? Como tal, a própria formação de professores e a produção de políticas curriculares configuram-se como demandas, em um jogo intrincado de uma condição duplicada. Recorro a Bhabha (2003) para discutir formação e currículo como duplo. Não se trata de um ou outro, mas formação e currículo, não como prolongamento de um em outro, ou simples movimento associativo, mas, como o autor, pondo em suspeita a noção de identidade inscrita no signo da semelhança que tenta fixar um objeto visível.

O autor questiona a centralidade da identidade como imagem e argumenta em favor de uma perspectiva que emerge no espaço discursivo, na significação. Para tanto, ele discute o processo de identificação como estratégia discursiva mobilizada por questões como cultura, política, significação e desejo. Assim, a partir desses tropos, o que nesse processo nos deparamos não é o sentido de profundidade, uma unidade originária, mas com uma dimensão de duplicação que, para ele, é "[...] o próprio princípio articulador do discurso" (BHABHA, 2003, p. 84).

Se a imagem visualizada busca objetificar, fixar, a duplicidade é encenada pelo "e", que aqui não implica um sentido de aditivo, mas que marca a tensão, o não binarismo; uma vez que é e ao mesmo tempo não é, marcando o lugar da ambivalência. É o desejo pelo outro que torna ambos - o eu e outro parciais, insuficientes em si mesmos. 
[...] a imagem como ponto de identificação - marca o lugar da ambivalência. Sua representação é sempre espacialmente fendida - ela torna presente algo que está ausente - e temporalmente adiada: é a representação de um tempo que está sempre em outro lugar, uma repetição. (BHABHA, 2003, p. 85).

A noção de duplo, de uma inscrição duplificada, perturbada pelo desejo do outro que cinde o eu, que fende a diferença e a identificação emerge como intervalo entre recusa e desejo, permite pensar formação e currículo rasurados. Nesse é não é, marca-se uma palavra e tenta-se apagá-la, mas nisso afirma-se a palavra e seu apagamento, seu apagamento a faz mais legível porque necessária. O que está sob rasura apresenta-se como indeterminação. No dizer de Derrida (2001, p. 12): “[...] por meio desse duplo jogo, marcado em certos lugares decisivos, por uma rasura que permite ler aquilo que ela oblitera, inscrevendo violentamente no texto aquilo que buscava comandá-lo de fora $[\ldots]$ ”.

Ao pensar as relações entre formação de professores e políticas curriculares como estando sob rasura, argumento, no alinhamento das contribuições de Bhabha e Derrida, que há uma perda de lugar original; e, sob rasura, formação e currículo duplicam-se e articulam-se, o que evidencia o jogo político na produção das políticas, tal como Mouffe (2003) diz ao diferenciar política e político. Entendendo a política como instância institucionalizada que se desdobra em ações de controle, determinação, prática e o político refere-se às relações de poder que se travam e inferem nas decisões/acordos/negociações feitas. O político é a dimensão do conflito, disputas e deliberações que estão intimamente relacionadas à prática política.

Assim, com formação e currículo sob rasura, apaga-se a fronteira delimitadora e fixada na medida em que estas são sempre presença/ausência, nunca realizadas totalmente. Essa duplicação, uma espacialização cindida em um entre-tempo, desestabiliza uma pretensa unidade tanto da formação de professores quanto das políticas curriculares.

A relação estreita entre questões tão centrais na discussão sobre a educação sempre se fez nítida - o que argumento é o entendimento de como elas se produzem mutuamente em meio a uma luta política, em um terceiro espaço, o "entre-lugar".

A intervenção do Terceiro espaço da enunciação, que torna a estrutura da significação e referência um processo ambivalente [...] É o terceiro espaço, que embora em si irrepresentável, constitui as condições discursivas da enunciação que garantem que o significado e os símbolos da cultura não tenham unidade ou fixidez primordial e até os mesmos signos possam ser apropriados, traduzidos, re-historicizados e lidos de outro modo. (BHABHA, 2003, p. 67-68). 
É possível delimitar o que cabe à formação e o que cabe às políticas curriculares? Se o limite implica fronteira, demarcação, ela também é deslocamento à medida que no atravessamento dessa fronteira, no entre-tempo/espaço que ela representa, a fronteira não se fixa, move-se no movimento de nossas aproximações e afastamentos. No dizer de Derrida (2004, p. 351):

Não se toca num limite, é uma diferença, um intervalo que escapa ao tato ou que é somente aquilo em que não se pode ou não se acredita poder tocar. Sem ser inteligível, o limite não é propriamente nem tangível, nem sensível. A experiência do limite "toca" em algo que não está plenamente presente. Um limite nunca aparece como tal.

Compreendida a impossibilidade dessa precisão, é possível afirmar que, na tensão provocada pela duplicação, há deslocamento e articulações que permitem significações, ainda que contingentes, e que estas tecem as enunciações para formação e currículo.

Problematizar a partir dessa perspectiva pode potencializar uma análise do processo político dessa relação e de projetos políticos-educacionais que, de forma clara, vinculam propostas de formação como instituidores de propostas curriculares. Não se trata de saber quem vem antes ou depois: formação ou currículo, mas de observar o continuum de dois polos e as articulações nesse espaço entre.

Em um jogo referencial, formação de professores e políticas curriculares não são em si, não são significantes, mas relações entre rastros, pois, com Derrida (2004), podemos entender que são processos que se alteram em permanência. É a ideia de rastro que expõe a vulnerabilidade, a tensão do tangível e o intocável, expõe o que é e o que não é e daí "[...] ele não pode senão se reinterpretar e sempre, finalmente, se deixar levar” (DERRIDA, 2004, p. 355).

Assim, as ações de formação continuada de professores não podem ser tomadas como isoladas ou subordinadas às políticas curriculares estabelecidas à priori, mas em uma relação que, negando uma anterioridade, se dá como uma articulação. $\mathrm{Na}$ formação não se re-apresenta uma dada política curricular, mas repete-se ou expõe-se essa política como rastro, em uma ação que mantém aberta a luta pela significação, pois não se assenta na literalidade, mas como contraassinatura, mesmo tendo como horizonte a fidelidade a um sentido visto como dado, o irrompe deixando sua marca.

Dessa forma, o que percebemos é um deslocamento das ações de formação como momentos de produção de políticas curriculares, em uma imbricação de significados, mobilizados por uma falta compartilhada: a qualidade, o que torna potente e produtiva a metáfora do pacto: compromisso, acordo, decisão a partir de uma composição que traz "muitos lados da história". Contudo, com que pactuamos? 


\section{O Pacto: que se propõe?}

$\mathrm{Na}$ apresentação da estrutura do Pacto, indica-se:

As Ações do Pacto apoiam-se em quatro eixos de atuação:

1. Formação continuada presencial para os professores alfabetizadores e seus orientadores de estudo;

2. Materiais didáticos, obras literárias, obras de apoio pedagógico, jogos e tecnologias educacionais;

3. Avaliações sistemáticas;

4. Gestão, mobilização e controle social. (BRASIL, [201-], s/p, grifo do autor).

Vê-se uma estrutura encadeada por ações de formação que se interligam necessariamente a práticas de avaliação universais e produção curricular, como se observa não só na estrutura do pacto, mas nas suas diretrizes delineadas na Portaria 867, de 4 de julho de 2012, que o institui:

Art. $2^{\circ}$ Ficam instituídas as ações do Pacto, por meio do qual o MEC, em parceria com instituições de ensino superior, apoiará os sistemas públicos de ensino dos Estados, Distrito Federal e Municípios na alfabetização e no letramento dos estudantes até o final do $3^{\circ}$ ano do ensino fundamental, em escolas rurais e urbanas, e que se caracterizam:

I - pela integração e estruturação, a partir do eixo Formação Continuada de Professores Alfabetizadores, de ações, materiais e referências curriculares e pedagógicas do MEC que contribuam para a alfabetização e o letramento; II - pelo compartilhamento da gestão do programa entre a União, Estados, Distrito Federal e Municípios;

III - pela garantia dos direitos de aprendizagem e desenvolvimento, a serem aferidos nas avaliações externas anuais. (BRASIL, 2012e).

Chama atenção uma ideia que é central no PNAIC e que mobiliza significados para a qualidade/melhoria pretendida: o direito de aprendizagem.

Os direitos de aprendizagem apresentam-se como eixos dos quais se desdobram os objetivos a serem alcançados pelos professores e orientam também o trabalho de formação. A discussão sobre os direitos de aprendizagem é desdobrada como decorrência do direito à educação, assegurado pela primeira vez na Constituição Federal de 1988:

Art. 205. A educação, direito de todos e dever do Estado e da família, será promovida e incentivada com a colaboração da sociedade, visando ao pleno desenvolvimento da pessoa, seu preparo para o exercício da cidadania e sua qualificação para o trabalho. [...] 
Art. 206. O ensino será ministrado com base nos seguintes princípios:

I - igualdade de condições para o acesso e permanência na escola [...]. (BRASIL, 1988, p. 137).

Daí o entendimento da educação como direito humano assegurado juridicamente. Andrade (2013) discute como esse direito tem sido visto principalmente como marco legal que garante acesso ao sistema escolar. $\mathrm{O}$ autor, ao discutir o marco axiológico que infere a educação como direito humano, propõe uma discussão filosófica que se assenta na tensão entre socialização e humanização e que traz um sentido em que a educação envolve a escolarização, mas está para além dessa, não se limita ao acesso e/ou permanência na escola. Interessa-me sublinhar a ideia desse questionamento feito pelo autor, pois ao longo da sua argumentação ele explora a educação como processo de humanização e daí, ainda que seja importante o aspecto legal que o sustenta, o ponto que precisa ser discutido incide na compreensão de que:

É importante apontar, numa reflexão axiológica sobre o direito à educação, para a multiplicidade dos procedimentos educativos, visto principalmente que educação não é somente escolar, mas um processo amplo de formação através do qual os humanos se fazem como tais. Insisto que a educação é um processo mais vasto do que estamos acostumados a entender em nosso cotidiano, pois se trata de um conjunto de reflexões, desejos e intervenções sobre a nossa convivência e sobre os meios pelos quais nos transformamos naquilo que somos. Assim, a educação é sempre múltipla, diversa, variada. Nunca é um processo uniforme, pois cada um e cada uma a vivencia como algo distinto, pessoal e intransferível. (ANDRADE, 2013, p. 26).

Há um deslocamento da questão do direito observado nos documentos do MEC que vai do apontamento da educação como direito humano à defesa a aprender. Dessa forma, se direito à educação de qualidade implica acesso ao conhecimento, o direito à educação desdobra-se em direitos de aprendizagem. Tal percepção alinha-se às análises que têm sido desenvolvidas por Biesta (2012), chamada de learnfication da educação, ou seja, a emergência e a centralidade de uma linguagem da aprendizagem que se faz foco dos discursos educacionais. O autor argumenta que não se trata de negar a importância desse foco na aprendizagem, mas chama atenção que este atende a uma das funções da educação: a qualificação. Para ele, há três funções da educação - qualificação, socialização, subjetivação que precisam ser pensadas de forma articulada. Assim, o autor convida à reflexão sobre a boa educação e não sobre a educação eficaz. Nessa perspectiva, a educação não pode ser vista apenas como escolarização, ao contrário do que se percebe como linha de argumentação que sustenta os direitos de aprendizagem tal como apresentados no Pacto - direito à escolarização, formalização de conteúdos ou mesmo a conteúdos de forma igualitária. 
Em verdade, a discussão acerca dos direitos de aprendizagem não se dá apenas no Pacto, mas em movimentos articulados: trata-se de fazer menção a um documento divulgado pelo MEC para consulta pública em 2012 (mesmo ano de instituição do Pacto) intitulado Elementos conceituais e metodológicos para definição dos direitos de aprendizagem e desenvolvimento do ciclo de alfabetização $\left(1^{\circ}, 2^{\circ}\right.$ e $3^{\circ}$ Anos) do Ensino Fundamental. Tal documento, aberto à consulta pública em 2013, constitui-se como etapa do que hoje vivenciamos no debate acerca de uma base comum nacional para o currículo da Educação Básica.

Ainda que, inicialmente, se apresente como um texto com fins de incitar a discussão coletiva, em sua apresentação é afirmado:

É plausível e urgente - por estar na base de todo o processo educativo - que se inicie esta tarefa pelo traçado das especificações curriculares para o Ciclo inicial de 1o a 30 ano do Ensino Fundamental, denominado Ciclo de Alfabetização.

É dentro destas balizas e sensível às necessidades sociais, políticas, culturais e econômicas do país que este documento apresenta ao Conselho Nacional de Educação (CNE) e à sociedade brasileira para debate (e operação) os Elementos Conceituais e Metodológicos para Definição dos Direitos e Objetivos de Aprendiragem e Desenvolvimento do Ciclo de Alfabetização das crianças brasileiras em idade escolar.

Este documento faz parte essencial de uma política de governo que está consubstanciada na MP No 586/2012 que foi anunciada pela Presidente da República no mesmo dia do lançamento do Pacto Nacional pela Alfabetizaçãa na Idade Certa, em novembro de 2012 com a assinatura de adesão de 5240 municípios e dos 27 estados da federação.

Tal Pacto Nacional supõe ações governamentais de cursos sistemáticos de Formação de professores alfabetizadores, oferecidos pelas Universidades Públicas participantes da Rede de Formação, a disponibilização de materiais pedagógicos fornecidos pelo MEC, assim como um amplo sistema de avaliações prevendo registros e análise de resultados que induzem ao atendimento mais eficaz aos alunos em seu percurso de aprendizagem.

As ações do Pacto Nacional pressupõem também gestão do processo, controle social e mobilização cujas responsabilidades estão repartidas entre os municípios, os estados e a união. (BRASIL, 2012d, p. 7, grifo do autor).

Ou seja, ainda que sob consulta, de certa forma, o Pacto materializa/ concretiza a formulação de uma política curricular para a alfabetização a partir da formação de professores imbuída dessas premissas, o que é explicitado no próprio documento:

Como consequência desse intenso trabalho colaborativo, este documento contém a definição de Direitos e Objetivos de Aprendizagem e Desenvolvimento para o Ciclo de Alfabetização. Os princípios e pressupostos 
fundamentais são aprofundados nos Cadernos de Formação do Pacto Nacional pela Alfabetização na Idade Certa, havendo, portanto, profunda articulação entre os pressupostos explicitados no presente documento e os textos inseridos no material do Pacto Nacional para a Alfabetização na Idade Certa, que será disponibilizado pelo MEC para orientar a prática docente a partir de 2013. (BRASIL, 2012d, p. 17).

Há, nessa discussão, um claro deslizamento de significação - se antes os planejamentos curriculares traziam a ênfase em expectativas de aprendizagem, agora, mais do que expectativas, há de garantir-se que isso se dê tendo em vista que é um direito.

Alferes e Mainardes (2014) observam também esse deslizamento em relação aos direitos de aprendizagem que parecem ter sido usados para substituir as expectativas de aprendizagem mencionadas nas DCN do Ensino Fundamental e que, em muitos contextos, foi amplamente criticada.

Penso que mais que substituição, é perceptível observar que, respaldados pela constituição e pela LDB, que diz sobre a incumbência na determinação de diretrizes (LDB) e conteúdos mínimos (Constituição Federal), a questão do deslocamento de expectativas para direitos expressa um giro no eixo de análise - as expectativas são mencionadas, mas sobre elas inferem outros fatores que possibilitam ou não que se concretizem pelos sujeitos; como direitos, há de preocupar-se que sejam assegurados sob pena de ferir os direitos dos sujeitos. Se as expectativas apontam possibilidades, a discussão dos direitos exige mecanismos de ação e concretização destes e de forma igualitária.

A transmutação de expectativas de aprendizagem ao direito de aprendizagem faz-se em um cruzamento do direito com igualdade e esse alinhamento de significação merece ser mais discutido. Que sentidos podemos dar à igualdade? Em um contexto contemporâneo de formulações amplas e com bases em diferentes matrizes sobre diferenças ou diversidade - destaco que, ao trazer os dois termos, não os trago como sinônimos, mas busco marcar o que afirmo quando me refiro a diferentes matrizes epistemológicas -, o que significa falar a partir da ideia de igualdade? Seria uma busca de organizar as diferenças?

Encontro em Butler e Laclau (2008) uma discussão que permite a problematização da questão. Os autores, em diálogo sobre os usos da igualdade, rechaçam a ideia de igualdade absoluta e como essa se relaciona com a perspectiva democrática que defendem. Eles chamam atenção para como no interior da ideia de igualdade há implícita a ideia de equivalência, ou seja, as diferenças são particularidades, especificidades, uma vez que há aspectos entre o que é considerado igual que são equivalentes. A problematização que os autores fazem sugere a necessidade de uma reelaboração do conceito de igualdade de forma que ele não implique em 
homogeneização, o que mina o jogo de diferenças que também a constitui. Isso seria fundamental de forma a politizar a discussão acerca dos direitos.

Requer-se a desnaturalização dos direitos tomados como absolutos, mantendo a tensão e a ambiguidade entre diferença, igualdade e democracia, de forma que igualdade não seja compreendida como normatividade. Sobre isso, Bhabha (2013) diz:

Meu trabalho é bem conhecido por suas formulações anti binárias e tentar reintroduzir a noção de contingência na conceituação de conflito cultural. Qualquer entendimento binário de lutas políticas e contradições culturais visa aliviar a ansiedade decorrente da própria natureza antagônica das relações culturais; na minha opinião, confinando o que uma vez foi uma tensão contraditória com a idéia de receptáculo gigante, consenso vertical e transcendente e deixa escapar possibilidades criativas da contingência, iteração e criatividade. É importante dar conta da nossa incapacidade de prever como, onde ou quando haveremos de conquistar os nossos direitos; além disso, é necessário que se abstenha de indicar qualquer discurso preditivo baseado em um plano geral transcendental ou teleológico. (BHABHA, 2013, p. 201, tradução nossa).

Com isso, o autor chama atenção que, ainda que discutindo direitos, este se faz contingentemente. Na releitura que ele faz da sua obra e na defesa que ele faz acerca dos direitos humanos, o pesquisador defende uma ética da hospitalidade, na perspectiva derridiana, que não se dá fundada em uma universalidade abstrata, mas que só é possível enunciando-se a partir de um terceiro espaço, no entre-lugar de negociação, ou seja, tratar-se-ia de uma universalidade contingente.

Essa marca da contingência é esvaziada na tomada do direito no alinhamento com igualdade como totalidade e identidade, como princípio em si e que abre caminho para o que é afirmado no Caderno de formação - Unidade 1, ano 1:

Para atender às exigências previstas nas Diretrizes, torna-se necessário delimitar os diferentes conhecimentos e as capacidades básicas que estão subjacentes aos direitos. Nos quadros a seguir, alguns conhecimentos e capacidades estão descritos e podem ser postos como pontos de partida para o estabelecimento do debate.

São descritos direitos de aprendizagem gerais, que permeiam toda a ação pedagógica e depois são expostos quadros com conhecimentos e capacidades específicos organizados por eixo de ensino da Língua Portuguesa: Leitura, Produção de textos Escritos, Oralidade, Análise Linguística. (BRASIL, 2012c, p. 31).

Ou seja, os próprios direitos não são postos em discussão - tomados em absoluto, convertem-se em "preditividade", ainda que, no material produzido sobre o Pacto, como um dos cadernos de formação e na parte que apresenta as orientações e os princípios para a formação de professores, se defenda que: 
[...] a formação de professores está intimamente ligada às questões do conhecimento, do currículo, das mudanças culturais e das novas tecnologias. $\mathrm{O}$ desenvolvimento de uma cultura de formação continuada, seja na escola ou em rede, depende de diversos fatores, dentre eles, dos compromissos institucional e individual.

O compromisso institucional (do Governo Federal e das secretarias de educação) reside principalmente na necessidade de promover espaços, situações e materiais adequados aos momentos de trabalho e reflexão, compreendendo que a formação continuada não é um treinamento no qual se ensinam técnicas gerais a serem reproduzidas. Se concebermos os professores como sujeitos inventivos e produtivos, sabemos que eles não serão repetidores em suas salas de aula daquilo que lhes foi aplicado na formação para orientar a sua nova prática. Sabemos sim que, a partir de diferentes estratégias formativas, eles serão estimulados a pensar sobre novas possibilidades de trabalho que poderão incrementar e melhorar o seu fazer pedagógico cotidiano. (BRASIL, 2012b, p. 27).

Na apresentação da estrutura da formação, observa-se: "Como está descrito no caderno de apresentação do Programa, o curso está organizado em oito unidades, totalizando 80 horas, além do seminário de encerramento de 08 horas [...]” (BRASIL, 2012b, p. 24). Em seguida, um quadro é apresentado (Figura 1).

Figura 1 - Organização da formação do Programa

\begin{tabular}{|c|c|c|}
\hline Unidade & Ano / Classe & Título Caderno \\
\hline \multirow{4}{*}{ (12 Honas) } & 1 & Currículo na alfabetização: concepções e princípios \\
\hline & 2 & $\begin{array}{l}\text { Currículo no ciclo de alfabetização: consolidação e } \\
\text { monitoramento do processo de ensino e de aprendizagem }\end{array}$ \\
\hline & 3 & Currículo inclusivo: o direito de ser alfabetizado \\
\hline & Educação do Campo & $\begin{array}{l}\text { Currículo no ciclo de alfabetização: perspectivas para uma } \\
\text { educação do campo }\end{array}$ \\
\hline \multirow{4}{*}{ (08) } & 1 & $\begin{array}{l}\text { Planejamento escolar: alfabetização e ensino da Língua } \\
\text { Portuguesa }\end{array}$ \\
\hline & 2 & $\begin{array}{l}\text { A organização do planejamento e da rotina no ciclo de } \\
\text { alfabetização na perspectiva do letramento }\end{array}$ \\
\hline & 3 & Planejamento e organização da rotina na alfabetização \\
\hline & Educação do Campo & Planejamento do ensino na perspectiva da diversidade \\
\hline
\end{tabular}

Fonte: Brasil (2012b, p. 24).

Nessa organização da formação, vê-se, então, uma proposição que, ao tomar os direitos em absoluto, vai se desdobrando em um sentido mais prático, em orientações do como fazer, em uma objetificação das ações, com prevalência na discussão de aspectos didático-metodológicos e na organização do conhecimento. 
Isso implica questionar os sentidos de currículo e ação docente que se desdobram e como articulações de significações para os referenciais a serem construídos seriam permitidas. Há uma evidente preocupação com a discussão curricular, na intenção da elaboração de princípios que orientem a construção de propostas curriculares, em um desdobramento do currículo como planejamento.

Nesse sentido, cabe discutir que referenciais são tomados para o desdobramento da discussão curricular e como são apropriados. As pistas estão na bibliografia básica recomendada no PNAIC. No que diz respeito a currículo indica-se:

\section{Currículo}

1 - MOREIRA, Antônio Flávio Barbosa; CANDAU, Vera Maria. Indagações sobre currículo: currículo, conhecimento e cultura. In BEAUCHAMP, Jeanete, PAGEL, Sandra Denise; NASCIMENTO, Aricélia Ribeiro. Indagações sobre o Currículo. Brasília: Ministério da Educação, Secretaria de Educação Básica, 2007. Disponível em: http://portal.mec.gov.br/seb/arquivos/pdf/Ensfund/indag3.pdf $O$ artigo aponta que o curriculo associa-se ao conjunto de esforcos pedagógicos desenvolvidos com intençoes educativas. Nesse contexto, os educadores possuem um papel fundamental na organização dos currículos que se materializam nas salas de aulas. (BRASIL, 2012c, $\mathrm{s} / \mathrm{p}$, grifo nosso).

Grifo na citação a justificativa/apresentação da indicação feita entendendo-a, também, como indicação de um modo de ler: o destaque para o que é considerado importante na discussão curricular, o que inicialmente indica a ênfase na organização do conhecimento, na dimensão do ensino.

Cruzando as proposições, no documento Elementos conceituais e metodológicos para definição dos direitos de aprendiragem (BRASIL, 2012d), sua estrutura está dividida em duas partes:

\section{Parte I}

FUNDAMENTOS GERAIS DO CICLO DE ALFABETIZACÃO $\left(1^{\circ}, 2^{\circ}\right.$ $E 3^{\circ}$ ANOS)

1. Contexto atual do movimento curricular no Ensino Fundamental

2. Ciclo de Alfabetização e Currículo: caminhos para assegurar o direito à aprendizagem

3. Ciclo de Alfabetização - Conceitos fundamentais: alfabetização e letramento

4. Ciclo de Alfabetização e Avaliação: diferentes possibilidades

Avaliação diagnóstica/ formativa/ sistêmica

Parte II DIREITOS E OBJETIVOS DE APRENDIZAGEM POR ÁREA

DE CONHECIMENTO [...]. (BRASIL, 2012d, p. 2, grifo do autor). 
Observa-se o destaque dado à questão curricular. Na apresentação geral do documento busca-se resumi-lo:

Sintese do documento: $\mathrm{O}$ presente documento está organizado em duas partes que contemplam os Fundamentos Gerais do Ciclo de Alfabetização, bem como os Direitos e Objetivos de Aprendiragem e Desenvolvimento por Área de Conbecimento e Componente Curricular de Lingua Portuguesa que se consubstanciam na aprendizagem das crianças de 6 a 8 anos. A Primeira Parte trata do contexto atual do movimento curricular no Ensino Fundamental e do conceito de aprendizagem como direito humano. Defende ainda a concepção de infância como universo singular dessa aprendizagem, tendo o currículo e o ciclo contínuo de aprendizagens como viabilização desses direitos. Tais conceitos são fundamentais para orientar essa trajetória, tendo em vista a avaliação e suas diferentes possibilidades de garantia dos Direitos. Na Segunda Parte, cada área de conhecimento e o componente curricular de língua portuguesa definem seus direitos de aprendizagens, os eixos que estruturam esses direitos e os diversos objetivos de aprendizagem de cada eixo, num rol que compõe cerca de 30 direitos, 20 eixos estruturantes e 256 objetivos de aprendizagem. Tem-se como próxima tarefa do MEC, após a aprovação pelo CNE, a elaboração de cadernos metodológicos que produzam reflexões de práticas sobre como efetivar os objetivos de aprendizagem nas milhares salas de aula em todo o território nacional. Sob a responsabilidade do MEC, o documento recebe agora o abrigo no CNE para nele ser analisado, debatido e normatizado. Lembrando que como texto de referência, é passível de ampliação depois de submetido às diversas vozes que ainda serão incluídas. Pretende-se assim recuperar os tantos anos desta dívida histórica de ter nossas crianças e jovens totalmente alfabetizados. É dívida, é direito de todos, obrigação do Estado e compromisso da sociedade. (BRASIL, 2012d, p. 8-9, grifo do autor).

Destaca-se o currículo como forma de garantia dos direitos, daí a discussão que centra na dinâmica curricular seus esforços. O item 1, que discute o movimento curricular contemporâneo, fazendo referência à produção cruzada entre currículo e alfabetização, em sua finalização, afirma:

No presente documento, o foco inicial do debate curricular, para o Ensino Fundamental, abrange os Direitos e Objetivos de Aprendizagem e Desenvolvimento para o Ciclo de Alfabetização $\left(1^{\circ}, 2^{\circ}\right.$ e $3^{\circ}$ anos), em Linguagem (Língua Portuguesa, Educação Física e Arte); Matemática; Ciências Humanas (História e Geografia); Ciências da Natureza. As razões que levam esse Ministério a priorizar neste momento o Ciclo de Alfabetização estão relacionadas às ações elencadas, anteriormente, e aos dados sobre os índices de analfabetismo e de baixa proficiência dos estudantes brasileiros nas habilidades de leitura e escrita. (BRASIL, 2012d, p. 15). 
A partir daí, o item 2 passa a dar destaque à discussão metodológica, em uma clara preocupação centrada em procedimentos pedagógicos e que, ao retomarmos a ligação com o Pacto, dá margens para a análise do que se propõe. Daí desdobra-se a questão que perpassa a formação: Alfabetizadores como curriculistas ou como executores?

O que se infere é a manutenção de uma lógica que destitui o professor de seu papel ativo na produção curricular, uma lógica em que ao professor cabe implementar e ter sua prática adequada e/ou condicionada por políticas curriculares que para ele são elaboradas. A problematização do contexto da prática feita apenas em termos de como ensinar minimiza o papel do professor na formulação curricular, reiterando a dicotomia que vê a prática como espaço de implementação e desenvolvimento de algo produzido para ela, sobre ela, mas exterior a ela. Ball, Bowe e Gold (1992) criticam tal acepção em sua análise da formulação de políticas curriculares problematizando a invisibilidade dos professores como também produtores de currículo, ainda que em outra esfera de produção.

Se a importância dos aspectos metodológicos e procedimentais faz-se importante e no campo da alfabetização apresentam-se como demanda dos professores, como é afirmado por vários autores (MORTATTI, 2013; SOARES, 2004, 2012; entre outros), é necessária a recuperação de tais aspectos. Destaca-se, assim, uma dicotomia percebida. Até a metade do século XX, a ênfase estava nos métodos e, depois, no como a criança aprende - colocadas, assim, como dimensões divorciadas na discussão sobre a alfabetização e não como instâncias que se interpenetram. Colocar o foco na dimensão do ensino apenas inverte os pólos, mas se mantém o fosso, ampliando-o ao homogeinizar os procedimentos de ensino.

Ao dar destaque a essa questão, o faço em concordância ao argumento de Macedo (2012) nas análises que ela faz das Diretrizes Curriculares Nacionais Gerais para a Educação Básica (2010). A autora defende a necessidade de pôr o ensino sob suspeita:

Partindo do movimento político que gerou as DCN ou dos fragmentos da teoria curricular que destaquei, quero problematizar o fato de o ensino ser visto como tarefa primordial da escola. Tomo isso como fato na medida em que, nos fragmentos que analisei, o conhecimento estava no centro do currículo. [...] A partir dessa conclusão sobre a primazia do ensino como função da escolarização, quero defender a necessidade de sua desconstrução. Para tanto, entendo ser fundamental redefinir os sentidos de currículo para além do conhecimento. (MACEDO, 2012, p. 734).

Não se trata de esvaziar a dimensão do ensino, mas reclamar que com ela possam dialogar outras dimensões que ampliem o sentido de alfabetização-formação-currículo que perpassa a própria significação do PNAIC. 


\section{Reticências...}

Meu intuito nessa reflexão sobre políticas curriculares-alfabetização-formação do alfabetizador foi, mais do que descrever que políticas estão sendo formuladas, lê-las a contrapelo, trazendo questionamentos que nos permitam entrar nessa conversa complicada, a partir do entendimento de que políticas e práticas são produções discursivas que disputam sentidos. Há de se por em debate os sentidos com os quais pactuamos, em um movimento que os observa não como fixação, mas que, em cada iteração, não se repita como dado antes, mas encenem-se novas perspectivas, o que aprendo com Bhabha (2003): cada repetição é diferente e diferencial.

O foco de análise foi a proposição do Pacto, os documentos que o apresentam e, assim, enunciam sentidos postos. Uma análise das ações do Pacto, nos diferentes contextos em que se desenvolvem, podem nos apresentar que disputas estão sendo travadas, como a política se move e se reconstitui.

Penso que uma das discussões centrais a serem feitas reside na problematização dos direitos de aprendizagem. Como os professores interpretam esses direitos? Como se articulam na formulação de políticas curriculares, projetos de trabalho que são desenvolvidos cotidianamente nas salas de aula que pactuam com ele? Como pensar direito de aprendizagem e as implicações de formulação de políticas de avaliação universais - podem elas afirmar a conquista de direitos?

Tantos direitos e penso que há de se responder também sobre os direitos dos professores alfabetizadores: seus direitos de aprendizagem e formação - aqui marco propositalmente o "e", retomando e defendendo também que aprendizagem e formação permeiem a discussão imagem duplificada.

Não se trata aqui de fazer um jogo de oposições - ou isto ou aquilo - ou aprendizagem ou formação -, mas observar como esses binarismos/polarizações reduzem a possibilidade de discussão. Direito a aprender é fundamental, mas articulado a dimensões outras. Retomo Biesta (2012): ao tratar das três funções da educação, o que nos re-apresenta é a complexidade e multirreferencialidade desse processo. Assim, se aprender é preciso, é também preciso que se pense no desenvolvimento de estratégias para consecução desse objetivo, educação não se esgota em aprendizagem. No que tange à alfabetização, o direito à conquista da leitura e da escrita precisa articular-se à formação de leitores e de escritores, da possibilidade de inscrição como sujeito na arena política. E isso para todos crianças e seus alfabetizadores.

Não se trata de negar questões caras à construção de uma proposta de alfabetização que seja efetiva, mas pô-las em negociação com outros sentidos. Diria como Machado de Assis, que as capas de algodão tem agora franjas de seda, 
como as de veludo tiveram franjas de algodão, ou seja, é essa permanência da diferença que garante a possibilidade de movimento, do porvir, em uma elaboração dialógica, que se dá no espaço intersubjetivo - o terceiro espaço - que seria o entre-lugar, interstício onde os sujeitos, a partir de seus múltiplos posicionamentos, se inter-relacionam. Essa formulação permite romper com a clausura de posições sectárias para a construção de um contexto dialógico que não apaga, mas tem sua diferença na produtividade. Skliar (2002) fala sobre as relações de alteridade na construção da pedagogia e diz que a busca da mesmice faz-nos incorrer em uma dupla negação: a negação da existência do outro e a negação de que esta possa ter ocorrido. Da negação à afirmação, a preocupação com a alfabetização e a formação de alfabetizadores dê-se na perspectiva da elaboração de propostas no que venho defendendo ao longo dos meus estudos: políticas de currículo, de alfabetização formação como políticas culturais.

\section{Referências}

ALFERES, M. A.; MAINARDES, J. Um Currículo Nacional para os Anos Iniciais? Análise preliminar do documento "Elementos conceituais e metodológicos para definição dos direitos de aprendizagem e desenvolvimento do ciclo de alfabetização $\left(1^{\circ}, 2^{\circ}\right.$ e $3^{\circ}$ anos) do Ensino Fundamental". Currículo Sem Fronteiras, v. 14, n. 1, p. 243-259, jan./abr. 2014.

ALMEIDA, C. S.; TASSONI, E. C. M. Entre cursos e discursos: o discurso político de formação de professores alfabetizadores no Programa Ler e Escrever no estado de São Paulo e a busca da escola de qualidade. In: REUNIÃO NACIONAL DA ANPED, 36., 2013, Goiás. Anais... Goiás: UFG, 2013. Disponível em: < http://36reuniao.anped.org.br/pdfs_trabalhos_aprovados/ gt10_trabalhos_pdfs/gt10_3168_texto.pdf>. Acesso em: 2 out. 2014.

ANDRADE, M. É a educação um direito humano? Em busca de razões suficientes para se justificar o direito de formar-se como humano. Revista Educação, Porto Alegre, v. 36, n. 1, p. 21-27, jan./abr. 2013.

BALL, S.; BOWE, R.; GOLD, A. Reforming education \& changing schools: case studies in Policy Sociology. New York: Routledge, 1992.

BAUER, A. Formação de Professores para Alfabetização: Avaliação de Impacto do Programa Letra e Vida. In: REUNIÃO ANUAL DA ANPED, 34., 2011, Natal. Anais... Natal: Centro de Convenções de Natal, 2011. Disponível em: <http://34reuniao.anped.org.br/images/ trabalhos/GT08/GT08-472\%20int.pdf> Acesso em: 2 out. 2014.

BHABHA, H. O local de cultura. Belo Horizonte: UFMG, 2003.

BHABHA, H. Nuevas minorías, nuevos derechos. Notas sobre cosmopolitismos vernáculos. Buenos Aires: SigloVeintiuno, 2013.

BIESTA, G. Boa educação na era da mensuração. Cadernos de Pesquisa, São Paulo, v. 42, n. 147, p. 808-825, dez. 2012. DOI: 10.1590/S0100-15742012000300009

BRASIL. Constituição (1988). Constituição da República Federativa do Brasil. Brasília. DF: Senado, 1988. 
BRASIL. Ministério da Educação. Pacto nacional pela alfabetização na idade certa Manual. Brasília: MEC/SEB, 2012a.

BRASIL. Ministério da Educação. Pacto nacional pela alfabetização na idade certa: formação de professores no Pacto nacional pela alfabetização na idade certa. Brasília: MEC/SEB, 2012b.

BRASIL. Ministério da Educação. Pacto nacional pela alfabetização na idade certa Caderno de formação - Unidade 1. Brasília: MEC/SEB, 2012c.

BRASIL. Ministério da Educação. Elementos conceituais e metodológicos para definição dos direitos de aprendizagem e desenvolvimento do Ciclo de Alfabetização $\left(1^{\circ}, 2^{\circ}\right.$ e $3^{\circ}$ anos) do Ensino Fundamental. Brasília: MEC/SEB, 2012d.

BRASIL. Ministério da Educação. Portaria no 867, de 4 de julho de 2012. Institui o Pacto Nacional pela Alfabetização na Idade Certa e as ações do Pacto e define suas diretrizes gerais. 2012. Diário Oficial da União, Brasília, 05 jul. 2012e.

BRASIL. Lei no 13.005, de 25 junho de 2014. Aprova o Plano Nacional de Educação - PNE e dá outras providências. Diário Oficial da União, Brasília, 26 jun. 2014.

BRASIL. Pacto Nacional pela Alfabetização na Idade Certa. Entendendo o Pacto. [201-]. Disponível em: <http://pacto.mec.gov.br/o-pacto>. Acesso em: 26 jun. 2015.

BRZEZINSKI, I. Formação de profissionais da educação (2003-2010). Brasília: MEC/ INEP, 2014. (Série Estado do Conhecimento, n. 13).

BUTLER, J.; LACLAU, E. Los usos de la igualdad. In: CRITCHEY, S.; MARCHART, O. (Comps.). Laclau aproximaciones criticas a su obra. Buenos Aires: Fondo de Cultura Economica, 2008. p. 117-139.

DERRIDA, J. Posições. Belo Horizonte: Autêntica, 2001.

DERRIDA, J. Papel Máquina. Tradução de Evando Nascimento. São Paulo: Estação Liberdade, 2004.

LACLAU, E. Emancipação e diferença. Rio de Janeiro: EdUERJ, 2011.

LOPES, A. C. Democracia nas políticas de currículo. Cadernos de Pesquisa, São Paulo, v. 42, n. 147, p. 700-715, set./dez. 2012. DOI: 10.1590/S0100-15742012000300003

LUCIO, E. O. A rede nacional de formação continuada de professores da Educação Básica e seu programa Pró-Letramento: Tecendo a rede das políticas contemporâneas para a formação docente a partir das perspectivas históricas e teórico-discursivas. In: REUNIÃO ANUAL DA ANPED, 34., 2011, Natal. Anais... Natal: Centro de Convenções de Natal, 2011. Disponível em: <http://34reuniao.anped.org.br/images/trabalhos/GT10/GT10-1126\%20int.pdf>. Acesso em: 2 out. 2014.

MACEDO, E. Como a diferença passa do centro à margem nos currículos: o exemplo dos PCNs. Educação \& Sociedade, Campinas, v. 30, n. 106, p. 87-109, jan./abr. 2009. DOI: 10.1590/S0101-73302009000100005

MACEDO, E. Currículo e conhecimento: aproximações entre educação e ensino. Cadernos de Pesquisa, São Paulo, v. 42, n. 147, p. 716-737, set./dez. 2012. DOI: 10.1590/S010015742012000300004

MACEDO, E. et al. Currículo da Educação Básica. Brasília: MEC/INEP, 2007. 
MORTATTI, M. R. L. Um balanço crítico da "Década da Alfabetização" no Brasil. Caderno CEDES, Campinas, v. 33, n. 89, p. 15-34, jan./abr. 2013. DOI: 10.1590/S010132622013000100002

MOUFFE, C. La paradoja democrática. Barcelona: Gedisa, 2003.

SOARES, M. Letramento e alfabetização: as muitas facetas. Revista Brasileira de Educação, Rio de Janeiro, n. 25, p. 5-17, jan./abr. 2004. DOI: /10.1590/S1413-24782004000100002

SOARES, M. Alfabetização e letramento. 6. ed. São Paulo: Contexto, 2012.

SKLIAR, C. A educação que se pergunta pelos outros: e se o outro não estivesse aqui? In: LOPES, A. C.; MACEDO, E. (Orgs.). Currículo: debates contemporâneos. São Paulo: Cortez, 2002. p. 196- 215.

Recebido em 30/10/2014

Aceito em 05/07/2015 